\title{
A Unique Researcher Identifier for the Physician Payments Sunshine Act
}

\section{Citation}

Carpenter, Daniel, and Steven Joffe. 2011. "A Unique Researcher Identifier for the Physician Payments Sunshine Act." JAMA 305 (19) (May 18). doi:10.1001/jama.2011.651.

\section{Published Version}

doi:10.1001/jama.2011.651

\section{Permanent link}

http://nrs.harvard.edu/urn-3:HUL.InstRepos:34257934

\section{Terms of Use}

This article was downloaded from Harvard University's DASH repository, and is made available under the terms and conditions applicable to Other Posted Material, as set forth at http:// nrs.harvard.edu/urn-3:HUL.InstRepos:dash.current.terms-of-use\#LAA

\section{Share Your Story}

The Harvard community has made this article openly available.

Please share how this access benefits you. Submit a story.

Accessibility 


\section{A Unique Researcher Identifier for the Physician Payments Sunshine Act}

Daniel Carpenter, $\mathrm{PhD}$

Steven Joffe, MD, MPH

T

he Physician Payments Sunshine Act (PPSA) PROMises a new era of transparency for the US health care system. Signed into law on March 23, 2010, the PPSA is part of the Patient Protection and Affordable Care Act of 2009. ${ }^{1}$ The PPSA requires medical product companies to report to the Department of Health and Human Services (DHHS) a range of "transfers of value" to covered recipients (physicians and teaching hospitals). With some exceptions, these transfers and their value will be publicly disclosed.

The PPSA constitutes an important step toward comprehensive, user-friendly, point-of-need availability of information about physicians' and investigators' financial relationships with industry. Ideally, any user of a major biomedical research database such as PubMed, clinicaltrials gov, or NIH RePORTER should be able to access a Web page listing an author's, investigator's, or grantee's financial relationships by following an embedded hyperlink. However, limitations of the PPSA will prevent realization of this ambitious vision. Straightforward, inexpensive measures to remedy these omissions would greatly enhance the value of the PPSA.

\section{Limits of the PPSA}

Data disclosed in response to the PPSA will be useful for many purposes, including greater consciousness of physician payments and increased ability to monitor physician behavior. These data will also facilitate independent analysis of the relationships between financial ties and research and clinical outcomes, not only allowing the research community to monitor conflicts of interest but also encouraging companies to scrutinize their financial relationships with individual researchers.

The PPSA, however, has important limitations. First, it does not cover payments to nonphysician investigators. Second, it does not incorporate a unique identifier that would permit linkages among databases. Although the PPSA requires companies to include physicians' National Provider Identifiers (NPIs) in their annual submissions to
DHHS, it explicitly prohibits DHHS from disclosing NPIs in its public reports-and in any case, NPIs would not encompass nonphysician recipients. Together, these limitations constrain the PPSA's reach and inhibit the ability of interested parties to use these data to understand the nature and effects of industry's financial relationships with the biomedical research enterprise.

These omissions are important because of pervasive concerns that industry financial relationships may contribute bias to research. ${ }^{2}$ Although the entity that funded a study is usually clearly identified, it is much more difficult to learn whether an investigator has received payments. This gap in available data gives rise to 3 related limitations. First, without unique investigator identifiers, universities and research hospitals have difficulty learning of payments to their faculty or staff. Second, investigators' incentives to be concerned about the fact or appearance of conflict of interest are diminished when their research cannot easily be linked to their financial relationships. Third, it is difficult to examine whether payments are linked to research outcomes. $^{3}$

\section{Remedying the Deficiencies in the PPSA}

The effectiveness of disclosure requires high-quality information that is accessible through a user-friendly interface. Four simple steps would allow the PPSA to fulfill its promise. First, an entity with access to payments data submitted to DHHS and the capability to function in a clearinghouse role could establish and administer a database of unique researcher identifiers. Second, DHHS could mandate that companies include recipients' researcher identifiers in their annual reports. Third, DHHS could include recipients' researcher identifiers in its annual public disclosure of companies' payments. Fourth, a means to incentivize registration of nonphysician and non-US investigators will be required. For example, institutional review boards might condition study approval on investigators' provision of their researcher

Author Affiliations: Department of Government, Harvard University, Cambridge, Massachusetts (Dr Carpenter); and Department of Pediatric Oncology, DanaFarber Cancer Institute, Boston, Massachusetts (Dr Joffe).

Corresponding Author: Daniel P. Carpenter, PhD, Department of Government, Harvard University, 1737 Cambridge St, Cambridge, MA 02138 (dcarpenter@gov .harvard.edu). 
identifiers, or biomedical journals might require inclusion of authors' researcher identifiers with submitted manuscripts.

Although several organizations could in theory administer the proposed system and its linkages to other databases, the National Library of Medicine (NLM) may be best positioned to perform this task. First, the NLM already houses many of the major databases that would be linked through the researcher identifier system. Second, as a component of DHHS, the NLM could fulfill the clearinghouse role without the administrative complexity required to move data between executive departments or outside the federal government.

The idea of a researcher identifier is hardly new. Several proposals, ${ }^{4-8}$ one of which seeks to establish "an alphanumeric string that uniquely identifies an individual scientist, much the way that a Digital Object Identifier (DOI) uniquely identifies a paper, book or other scholarly publication," 8 are currently circulating. The goal of existing proposals is to minimize attribution error (ie, attributing an article to the wrong "D Smith"). ${ }^{5}$ The potential of a unique identifier to foster transparency of financial relationships in biomedical research has not, however, been previously recognized.

The federal government has long required the registration and unique identification of physicians as well as of organizations such as hospitals and health plans. Thus, ample legal authority exists for the creation of these identifiers through rulemaking.

\section{Benefits of a Unique Researcher Identifier}

With a system of unique researcher identifiers in place, readers of articles or abstracts using PubMed or other online bibliographic databases would be able to hyperlink to a publicly available page listing the investigator's payments. Similarly, patients and others seeking studies on clinicaltrials.gov would be able to access data on investigators' financial relationships. In addition, analysts would be able to examine whether payments are concentrated among certain kinds of researchers or in certain subfields of research, as well as whether they are systematically associated with particular research outcomes.

Many of the benefits of disclosure systems come from recipients' knowledge that their behavior is being observed. Given the ease of access and aggregation associated with a unique identifier, researchers would be induced to think more carefully about the payments they accept. Companies may police their payment patterns more carefully. The claim that payments are directed to the scholars with the greatest expertise can be rigorously tested.

Although any such system has limitations, these are likely to be modest relative to the gains. Investigators would have one-time compliance costs for a system that would serve other purposes. Given the current administration's transparency initiative, ${ }^{9}$ the net cost of informatics and Web hosting would likely be modest. With the prior existence of both the PPSA and a nascent researcher identification system, it is unlikely that the present proposal would chill scientific discovery. Moreover, although nonphysician and non-US investigators would not initially be covered (the PPSA does not mandate disclosure of payments to these professionals), a researcher identifier would create a basis for extending disclosure, through voluntary efforts or future mandates, to these scientists. Recent efforts to compel Public Health Service-funded researchers to disclose their financial relationships are a step in this direction, ${ }^{10}$ but are limited in that many investigators do not receive Public Health Service funding.

\section{Conclusion}

The goal of PPSA-to enhance transparency of financial relationships between the medical products industry and those individuals who influence the practice of medicine or the conduct of research-is a worthy one. The development of a unique identifier system that permits linkage of individuals' payments data to their entries in major biomedical research databases and facilitates extension of disclosure practices to nonphysician investigators will enhance the likelihood that the PPSA will achieve its important goal.

Conflict of Interest Disclosures: Both authors have completed and submitted the ICMJE Form for Disclosure of Potential Conflicts of Interest. Dr Joffe reports being a paid member of a data monitoring committee for Genzyme Corporation (now a part of sanofi-aventis). Dr Carpenter reported no disclosures.

Funding/Support: This work was supported by grant 1UL1RR025758-01 from the Harvard Catalyst (Drs Carpenter and Joffe) and support from the Safra Center for Ethics, Harvard University (Dr Carpenter), Alfred Sloan Foundation (Dr Carpenter), and Greenwall Foundation (Dr Joffe).

Role of the Sponsor: No sponsor or funder had any role in the preparation, review, or approval of the manuscript.

\section{REFERENCES}

1. Pub L No. 111-148, 124 Stat 1025 (2010).

2. US Institute of Medicine. Conflict of Interest in Medical Research, Education, and Practice. Washington, DC: National Academy of Sciences; 2009.

3. Chimonas S, Frosch Z, Rothman DJ. From disclosure to transparency: the use of company payment data. Arch Intern Med. 2011;171(1):81-86.

4. Cals JW, Kotz D. Researcher identification: the right needle in the haystack. Lancet. 2008;371(9631):2152-2153.

5. Bohne-Lang A, Lang $E$. Do we need a unique scientist ID for publications in biomedicine? Biomed Digit Libr. 2005;2(1):1.

6. Enserink M. Scientific publishing: are you ready to become a number? Science. 2009;323(5922):1662-1664.

7. Friedberg EC. Good news on the horizon: the Open Researcher and Contributor ID (ORCID). DNA Repair (Amst). 2010;9(2):102

8. Credit where credit is due. Nature. 2009;462(7275):825.

9. US Government Web site. http://www.data.gov/. Accessed April 21, 2011. 10. US Department of Health and Human Services. Responsibility of applicants for promoting objectivity in research for which public health service funding is sought and responsible prospective contractors: request for comments. Fed Regist. 2009; 74(88):21610-21613. 